\title{
Assessment of patient safety culture: a nationwide survey of community pharmacists in Kuwait
}

Fatemah Mohammad Alsaleh ${ }^{1 *}$, Eman Ali Abahussain ${ }^{1}$, Hamed Hamdi Altabaa', Mohammed Faisal Al-Bazzaz ${ }^{1}$ and Noor Barak Almandil ${ }^{2}$

\begin{abstract}
Background: Medication errors have been the largest component of medical errors threatening patient safety worldwide. Several international health bodies advocate measuring safety culture within healthcare organizations as an effective strategy for sustainable safety improvement. To the best of our knowledge, this is the first study conducted in a Middle Eastern country at the level of community pharmacy, to examine safety culture and to evaluate the extent to which patient safety is a strategic priority.

Methods: A descriptive cross-sectional study was conducted. The Pharmacy Survey on Patient Safety Culture (PSOPSC), developed by the Agency for Healthcare Research and Quality (AHRQ), was used to collect data. PSOPSC is a selfadministered questionnaire which was previously tested for validity and reliability. The questionnaire was distributed among pharmacists who work in community pharmacies from the five governorates of Kuwait (Capital, Hawalli, Farwaniya, Jahra, and Ahmadi). The Statistical Package for Social Science (SPSS) software, version 24 was used for analysing data.

Results: A total of 255 community pharmacists from the five governorates were approached to participate in the study, of whom 253 returned a completed questionnaire, with the response rate of $99 \%$. Results from the study showed that patient safety is a strategic priority in many aspects of patient safety standards at the level of community pharmacies. This was reflected by the high positive response rate (PRR) measures demonstrated in the domains of "Teamwork" (96.8\%), "Organizational Learning-Continuous Improvement" (93.2\%) and "Patient Counselling" (90.9\%). On the other hand, the lowest PRR was given to the "Staffing, Work Pressure, and Pace" domain which scored 49.7\%.

Conclusions: Understanding community pharmacists' perspectives of patient safety culture within their organization is critical. It can help identify areas of strength and those that require improvement, which can help support decision about actions to improve patient safety. The current study showed that urgent attention should be given to the areas of weakness, mainly in the dimension of "Staffing, Work Pressure and Pace." The pharmacists pointed the need for adequate breaks between shifts and less distractible work environment to perform their jobs accurately.
\end{abstract}

Keywords: Safety culture, Community pharmacists, Kuwait

\footnotetext{
* Correspondence: fatemah.alsaleh@hsc.edu.kw

1 Department of Pharmacy Practice, Faculty of Pharmacy, Kuwait University,

P.O. Box 24923, 13110 Safat, Kuwait

Full list of author information is available at the end of the article
}

(c) The Author(s). 2018 Open Access This article is distributed under the terms of the Creative Commons Attribution 4.0 International License (http://creativecommons.org/licenses/by/4.0/), which permits unrestricted use, distribution, and reproduction in any medium, provided you give appropriate credit to the original author(s) and the source, provide a link to the Creative Commons license, and indicate if changes were made. The Creative Commons Public Domain Dedication waiver (http://creativecommons.org/publicdomain/zero/1.0/) applies to the data made available in this article, unless otherwise stated. 


\section{Background}

Patient safety, defined as "the freedom from accidental injuries during the course of medical care; activities to avoid, prevent, or correct adverse outcomes which may result from the delivery of healthcare [1]" is a critical element of healthcare quality and has been a public concern across all healthcare systems worldwide. Medication errors, defined as "any preventable events that may cause or lead to inappropriate medication use or patient harm while the medication is in the control of the healthcare professional, patient, or consumer" [2], are a common component of medical errors threatening patient safety $[2,3]$. They are estimated to be the $8^{\text {th }}$ leading cause of death in the US and are responsible for the death of approximately 44.000 to 98.000 people every year $[1,4]$. While all medication errors are preventable, $28 \%$ of Adverse Drug Events (ADE), defined as "injuries resulting from medical interventions related to a drug" [2], are preventable and pharmacists can play a pivotal role in preventing $50 \%$ of them [5]. Studies have shown that pharmacist intervention can help to improve patient safety and quality of care [6,7].

Promoting a "culture of safety" within healthcare systems has become one of the major pillars for optimizing patient safety. Following the report from the US Institute of Medicine (IOM) in 1999 [1], there has been a growing recognition within the healthcare systems of the need for transforming an organizational culture to improve patient safety. The safety culture of an organization is the product of individual and group values, attitudes, perceptions, competencies, and patterns of behaviour that determine the commitment to the style and proficiency of an organization's health and safety management [4]. Achieving a culture of safety requires an understanding of the values, beliefs and norms regarding health and safety within an organization, thus it is vital to unveil the underlying cultural factors present within the organization so that safety culture can be transformed $[8,9]$. Frameworks, surveys and assessment tools have been designed over the past decade to measure and understand the type of culture that exists within healthcare organizations and to identify the areas of strengths and gaps $[8,10-14]$.

On a global basis, several international health bodies, such as the World Health Organization (WHO) and the Joint Commission International (JCI) advocate measuring safety culture within healthcare organizations as an effective strategy for sustainable safety improvement. A recent systematic review assessing the status of patient safety culture in the Arab countries called for the need to promote patient safety culture for improving patient safety in the Arab World [15].

There has been an intensive effort by the Ministry of Health $(\mathrm{MoH})$ in Kuwait to ensure that the healthcare delivery meets the international standards. Accreditation Canada International (ACI) was commissioned in Kuwait to introduce a national accreditation program to be adopted by government hospitals and polyclinics [16]. On the other hand, the community pharmacy setting had less attention and therefore conducting this study is of utmost importance to explore the status of patient safety and to call for recommendations wherever necessary.

Few studies on safety culture were published in Kuwait [17-19]. However, none were surveyed among community pharmacists. To the best of our knowledge, this is the first study in the Middle East conducted in the community pharmacy setting to evaluate whether the practice of community pharmacists support patient safety and the extent to which safety is a strategic priority.

\section{Methods}

\section{Aim of the study}

The study aimed at evaluating whether the practice of community pharmacists in Kuwait supports patient safety and the extent to which safety is a strategic priority.

\section{Study design \& settings}

A descriptive cross-sectional study was conducted, using a pre-tested self-administered questionnaire. The questionnaire was distributed among pharmacists who work in community pharmacies from the five governorates of Kuwait.

\section{Sample size calculation and sampling strategy}

Due to the unavailability of a list with the names and addresses of all community pharmacists, a list of the entire community pharmacies in the country was initially obtained from $\mathrm{MoH}$. At the time of the study, a total of 454 community pharmacies were available and were scattered across the five health governorates in Kuwait [Capital (48), Hawalli (160), Jahra (48), Farwaniya (89), Ahmadi (109)]. The sample size was calculated based on the results of a previous similar study in Kuwait, where the response distribution of the main questions were $38 \%$ [18]. Minimum sample size of 202 was required at 95\% confidence interval and 5\% margin of error (Rao$\mathrm{soft}^{\circ}$ software). Assuming a response rate of $80 \%$, larger sample was targeted. The community pharmacies were first stratified at the level of the governorates. Then, a proportional percentage of the number of pharmacies to be selected from each governorate was calculated. The selection of pharmacies from the original list was carried out at the level of each governorate using systematic random sampling.

\section{Study tool}

The Pharmacy Survey on Patient Safety Culture (PSOPSC), developed by the Agency for Healthcare 
Research and Quality (AHRQ); community pharmacy version, was used to collect data for the study [20] (Additional file 1). It includes 36 items that measure 11 dimensions of patient safety culture. In addition, the survey includes 3 items about the frequency of documenting mistakes, 3 items about respondent's demographics, an overall rating question and a section for open-ended comments. Additional questions were added to the demographic section of the original questionnaire. The PSOPSC is a validated tool, and the reliability of its dimensions and their items have been proven [20]. The items for the parts were measured using the 5-point Likert response scale of agreement (Strongly Disagree to Strongly Agree) or frequency (Never to Always). The questionnaire was distributed in its original language (English).

\section{Ethics approval}

Ethical clearance was sought from the Standing Committee for Coordination of Health and Medical Research, $\mathrm{MoH}$ and the Health Science Centre (HSC) Ethics Committee for Student Research, Kuwait University. Data was collected over a period of 5 months (January to May 2017).

\section{Inclusion and exclusion criteria}

The study included pharmacists working in the community pharmacies, including the pharmacies of the cooperative societies. Other workers such as pharmacy helpers, cashiers and cleaners were excluded.

\section{Sample recruitment and data collection}

Initially, a pilot study was carried out to ensure that the questions were clear and reflect the objectives of the study. Ten community pharmacies were selected randomly from the original list. Community pharmacists were invited verbally to participate. Before distributing the questionnaires, aim and objectives of the study were fully explained. If the pharmacy employed more than one pharmacist, then only one was invited to participate. A consent form was given to those who were willing to participate to assure their participation is voluntary. All collected information were kept confidential and anonymous. The questionnaire was collected back on the same day.

\section{Data analysis}

The Statistical Package for Social Science (SPSS) software, version 24 was used for analysing the data. Data from closed-ended questions were coded and entered into the SPSS. The respondents' demographics were presented using descriptive statistics; frequency/percentages, mean \pm standard deviation (SD) and median or interquartile range (IQR). Calculation of composite frequencies for the 11 patient safety dimensions was carried out according to the instructions of the user's guide published by the AHRQ [20].
The pharmacists' perception about patient safety culture in their organizations is critical to achieve patient safety standards. Therefore, the study focused on measuring the positive response rate (PRR) as it illustrates pharmacist's points of view on the different domains of patient safety culture in their setting. The PRR of the survey questions was calculated using the formula by the User's Guide of PSOPSC [20]. Responses like "Does Not Apply/ Don't Know" and missing responses were excluded when displaying the percentage of responses to the survey items. Chi square and Fisher's exact testes were used, with a significance level of $p<0.05$.

\section{Results}

A total of 255 community pharmacists from the five governorates were approached to participate in the study, of whom 253 have returned the completed questionnaire, giving a response rate of $99 \%$. The sociodemographic characteristics of the participants are shown in Table 1.

\section{Safety culture assessment across all the community pharmacies in Kuwait}

The pharmacists' perception about patient safety culture in their organizations is shown in Table 2.

The standards of optimal patient safety were observed in the dimensions of "Teamwork" which scored the highest PRR (96.8\%), followed by the "Organizational Learning-Continuous Improvement" and "Patient Counselling" domains which scored 93.2 and $90.9 \%$, respectively. In general, there were more positive than negative responses to individual survey items and the positive responses ranged from 27.1 to $97.6 \%$. An overall PRR of $83.8 \%$ was scored for all the 36 items. Table 2 displays the detailed scores.

Pharmacists' overall perceptions of patient safety in their pharmacies were assessed by 3 items. The participants reported that the patient safety is never forgone to achieve more sales $(n=175 ; 70.6 \%)$; patient safety is a priority $(n=241 ; 96.0 \%)$; and pharmacy is good at preventing mistakes $(n=242 ; 95.7 \%)$. The pharmacists were also asked about the frequency of mistakes reporting within the pharmacy and tabulated as shown in Table 3. Regardless of the seriousness of the mistakes, they were never or rarely documented in most of the cases.

\section{Safety culture assessment at the level of governorates in Kuwait}

There were statistically significant differences between the governorates in the dimensions relevant to pharmacy's physical layout (A7), staff training (A3 and A10), patient counselling (B7), work pressure and pace (B3, B9 and B16), communication about mistakes (B13), and overall perception about the pharmacy (C3) (Table 4). Regardless, a trend of similarity was observed with some 
Table 1 Socio-demographic characteristics of participants $(n=253)$

\begin{tabular}{|c|}
\hline Gender \\
\hline Male \\
\hline Female \\
\hline Age (years) \\
\hline $20-29$ \\
\hline $30-39$ \\
\hline $40-49$ \\
\hline$\geq 50$ \\
\hline Mean (SD) \\
\hline Nationality \\
\hline Egyptian \\
\hline Syrian \\
\hline Jordanian \\
\hline Indian \\
\hline Pakistani \\
\hline Palestinian \\
\hline Years of experience \\
\hline$<5$ \\
\hline $6-10$ \\
\hline $11-15$ \\
\hline $16-20$ \\
\hline$>20$ \\
\hline
\end{tabular}

Median (IQR)

Country of graduation

Egypt
Syria
Jordan
India
Pakistan

Last degree in Pharmacy

Bachelor 234

Pharm D 7

Master 11

Other

Years of experience in the present Pharmacy

$\begin{array}{ll}<6 \text { months } & 11 \\ 6 \text { months to }<1 \text { year } & 26 \\ 1 \text { year to }<3 \text { years } & 89\end{array}$

Table 1 Socio-demographic characteristics of participants $(n=253)$ (Continued)

\begin{tabular}{lll}
\hline & $\mathrm{n}$ & $(\%)$ \\
\hline 3 years to $<6$ years & 65 & $(25.7)$ \\
6 years to $>12$ years & 46 & $(18.2)$ \\
$\geq 12$ years & 16 & $(6.3)$ \\
Working hours per week in this pharmacy & \\
$32-40$ & 28 & \\
$>40$ & 225 & $(11.1)$ \\
& & $(88.9)$ \\
Governorate & & \\
Capital & 27 & $(10.7)$ \\
Hawalli & 89 & $(35.2)$ \\
Farwaniya & 50 & $(19.8)$ \\
Jahra & 27 & $(10.7)$ \\
Ahmadi & 60 & $(23.7)$ \\
\hline
\end{tabular}

$S D$ standard deviation, IQR interquartile range

items in Farwaniya, Ahmadi and Jahra governorates, compared to the Capital and Hawalli (Table 4).

There was significantly $(p<0.001)$ less PRR observed in Farwaniya, Ahmadi and Jahra in terms of the adequacy of breaks during shifts compared to the Capital and Hawalli. More pharmacists in the Capital and Hawalli governorates felt $(\mathrm{p}<0.001)$ rushed when processing prescriptions or were bothered with frequent interruptions. With respect to the patient counselling time, pharmacists in Hawalli governorates showed significantly $(p=0.035)$ less PRR than pharmacists in other governorates. Pharmacists in Hawalli also showed a significantly $(p=0.019)$ less PRR regarding the communication and discussion of any mistakes happened in the pharmacy (Table 4).

Regarding the perception of patient safety, although most of the pharmacists in every governorate disagreed that the pharmacies place more emphasis on sales rather than patient safety (C3), the disagreement was significantly $(p=0.005)$ less among pharmacists working in Farwaniya, Ahmadi and Jahra.

\section{Assessment of community pharmacies patient safety} culture according to the pharmacists' years of experience The PRR for individual items, as well as the average rates for the 11 PSOPSC dimensions, were computed separately for the three groups of pharmacists according to their years of experience in the present community pharmacy ( $<3$ years, 3 to 5 years, and $\geq 6$ years) (Table 5 ). Pharmacists having experience of 6 years or more significantly thought that both pharmacy assistants (A3) and staff members (A10) receive adequate training ( $p=$ 0.005 and $p=0.004$, respectively) compared with those 
Table 2 Positive response rate (PRR) of individual items and dimensions across all community pharmacies $(n=253)$

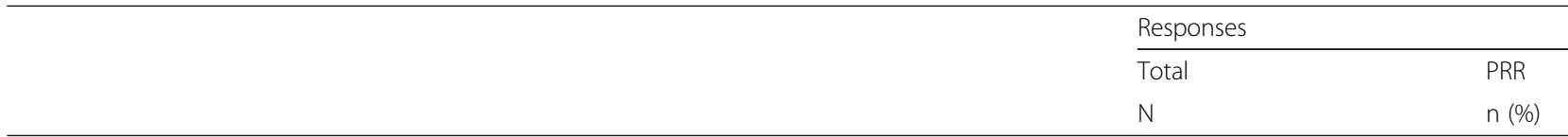

1. Physical Space and Environment (dimension positivity 88.2\%)

A1. This pharmacy is well organized

A5. This pharmacy is free of clutter/untidiness

A7. The physical layout of this pharmacy supports good workflow

2. Team Work (dimension positivity 96.8\%)

A2. Staff treat each other with respect

A4. Staff in this pharmacy clearly understand their roles \& responsibilities

A9. Staff work together as an effective team

3. Staff training and Skills (dimension positivity 89.5\%)

A3. Pharmacy assistants/helpers in this pharmacy receive the training they need to do their jobs

A6. Staff in this pharmacy have the skills they need to do their jobs well

A8. Staff who are new to this pharmacy receive adequate orientation

4. Communication Openness (dimension positivity $84.4 \%$ )

B1. Staff ideas and suggestions are valued in this pharmacy

B5. Staff feel comfortable asking questions when they are unsure about something

B10. It is easy for staff to speak up to their pharmacy manager in this pharmacy

\section{Patient Counselling (dimension positivity 90.9\%)}

B2. Pharmacists in this pharmacy encourage patients to talk about their

B7. Our pharmacists spend enough time talking to patients about how to use their medications

6. Staffing, Work Pressure, and Pace (dimension positivity 49.7\%)

B3. Staff take adequate breaks during their shifts

B16. Interruptions/distractions in this pharmacy (from phone calls, faxes, customers, etc.) make it difficult for staff to work accurately $(\mathbf{R})$

7. Communication about Prescriptions across Shifts (dimension positivity 74.6\%)

B4. We have clear expectations about exchanging important prescription 
Table 2 Positive response rate (PRR) of individual items and dimensions across all community pharmacies $(n=253)($ Continued)

\begin{tabular}{|c|c|c|}
\hline & \multicolumn{2}{|c|}{ Responses } \\
\hline & Total & PRR \\
\hline & $\mathrm{N}$ & n (\%) \\
\hline \multicolumn{3}{|l|}{ 8. Communication about Mistakes (dimension positivity $81.8 \%$ ) } \\
\hline B8. Staff in this pharmacy discuss mistakes & 253 & $212(83.8)$ \\
\hline B13. When patient safety issues occur in this pharmacy, staff discuss them & 252 & $206(81.7)$ \\
\hline $\begin{array}{l}\text { B15. In this pharmacy, we talk about ways to prevent mistakes from } \\
\text { happening again }\end{array}$ & 252 & $201(79.8)$ \\
\hline \multicolumn{3}{|l|}{ 9. Response to Mistakes (dimension positivity $85.3 \%$ ) } \\
\hline C1. Staff are treated fairly when they make mistakes & 251 & $235(93.6)$ \\
\hline $\begin{array}{l}\text { C4. This pharmacy helps staff learn from their mistakes rather than } \\
\text { punishing them }\end{array}$ & 251 & $234(93.2)$ \\
\hline $\begin{array}{l}\text { C7. We look at staff actions and the way we do things to understand } \\
\text { why mistakes happen in this pharmacy }\end{array}$ & 252 & $220(87.3)$ \\
\hline C8. Staff feel like their mistakes are held against them $(\mathbf{R})$ & 247 & $186(75.3)$ \\
\hline \multicolumn{3}{|l|}{ 10. Organizational Learning - Continuous Improvement (dimension positivity 93.2\%) } \\
\hline $\begin{array}{l}\text { C2. When a mistake happens, we try to figure out what problems in the } \\
\text { work process led to the mistake }\end{array}$ & 252 & $237(94.0)$ \\
\hline C5. When the same mistake keeps happening, we change the way we do things & 249 & $225(90.4)$ \\
\hline C10. Mistakes have led to positive changes in this pharmacy & 250 & $238(95.2)$ \\
\hline \multicolumn{3}{|l|}{ 11. Overall Perceptions of Patient Safety (dimension positivity 87.5\%) } \\
\hline C3. This pharmacy places more emphasis on sales than on patient safety $(\mathbf{R})$ & 248 & $175(70.6)$ \\
\hline C6. This pharmacy is good at preventing mistakes & 253 & $242(95.7)$ \\
\hline $\begin{array}{l}\text { C9. The way we do things in this pharmacy reflects a strong focus on } \\
\text { patient safety }\end{array}$ & 251 & $241(96.0)$ \\
\hline
\end{tabular}

(R): Negatively worded items were reversed coded

with less experience. Also, the average rate for "Staff Training and Skills" dimension was significantly higher among those with experience of 6 years or more compared to the less experienced groups $(p=0.001)$. Pharmacists with experience of 6 years or more believed that the staff members take adequate breaks during their shifts compared with those with less experience (B3, $p<$ 0.001). The PRR for the items "we feel rushed when processing prescriptions (B9)" $(\mathrm{p}=0.005)$ and "interruptions/distractions in this pharmacy make it difficult for staff to work accurately (B16)" ( $p=0.001)$ was significantly lower among pharmacists with more than 6 years of experience compared to the less experienced groups.

\section{Assessment of community pharmacies patient safety culture according to the number of working hours per week of the pharmacists in the present community pharmacy}

Pharmacists who worked $40 \mathrm{~h}$ per week or less scored significantly $(p=0.024)$ higher average rate for the "Staff Training and Skills" dimension compared to those who worked more than $40 \mathrm{~h}$ per week (Table 6). On the other

Table 3 Frequency of events reported by the community pharmacists $(n=253)$ from the five governorates

\begin{tabular}{|c|c|c|c|c|}
\hline In this pharmacy, how often the following types of mistakes documented? & $\begin{array}{l}\text { Never/Rarely } \\
\mathrm{n}(\%)\end{array}$ & $\begin{array}{l}\text { Sometimes } \\
\mathrm{n}(\%)\end{array}$ & $\begin{array}{l}\text { Most of the } \\
\text { time/Always } \\
\mathrm{n}(\%)\end{array}$ & $\begin{array}{l}\text { PRR } \\
\mathrm{n}(\%)\end{array}$ \\
\hline $\begin{array}{l}\text { D1. When a mistake reaches the patient and could cause harm but does not, } \\
\text { how often is it documented? }\end{array}$ & $143(56.6)$ & $60(23.7)$ & $44(17.4)$ & $44(17.4)$ \\
\hline $\begin{array}{l}\text { D2. When a mistake reaches the patient but has no potential to harm the } \\
\text { patient, how often is it documented? }\end{array}$ & $147(58.1)$ & $60(23.7)$ & $39(15.4)$ & $39(15.4)$ \\
\hline $\begin{array}{l}\text { D3. When a mistake that could have harmed the patient is corrected } \\
\text { BEFORE the medication leaves the pharmacy, how often is it documented? }\end{array}$ & $154(60.8)$ & $53(20.9)$ & $40(15.8)$ & $40(15.8)$ \\
\hline
\end{tabular}


Table 4 Positive response rate (PRR) on individual items and dimensions at the level of the governorates

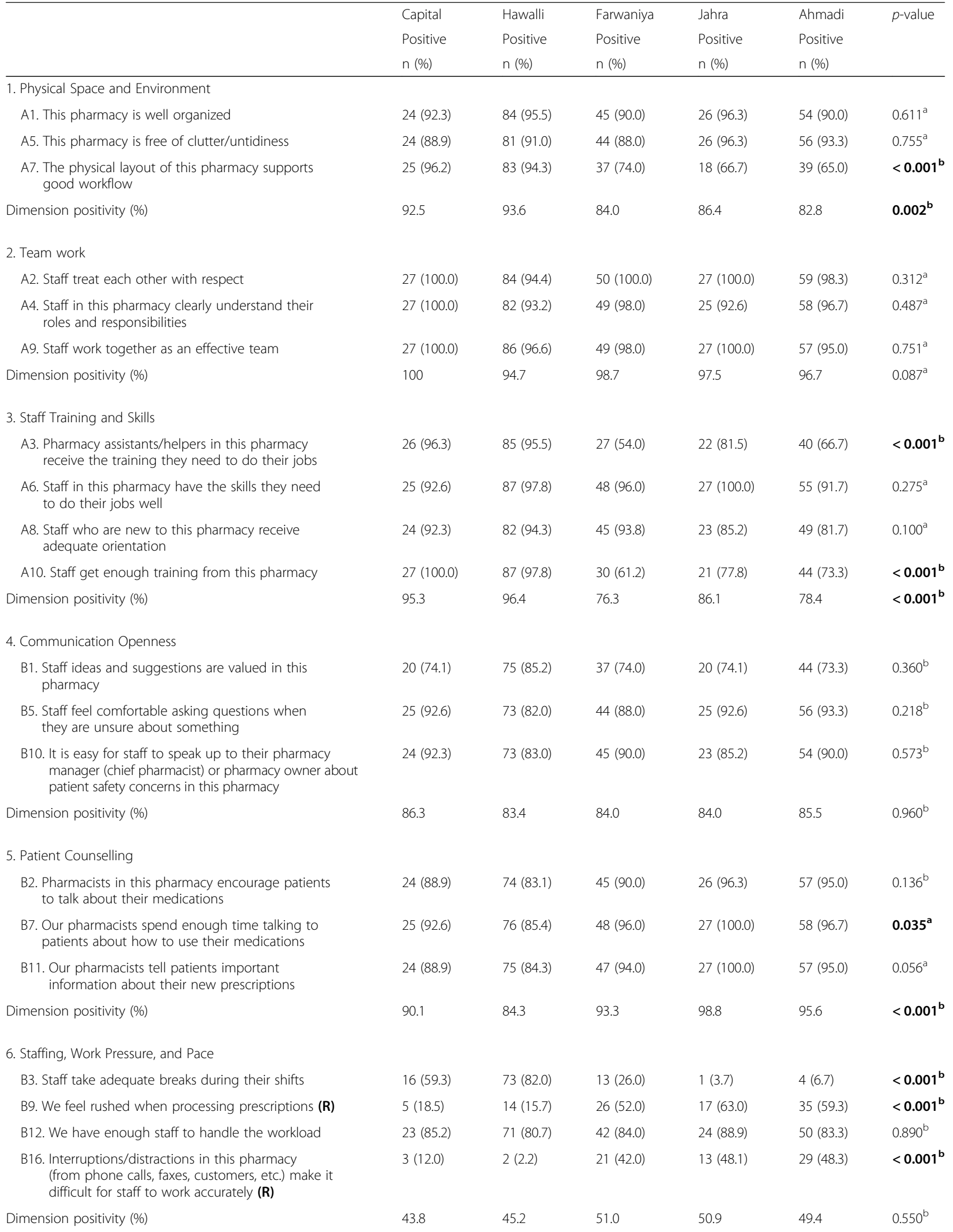


Table 4 Positive response rate (PRR) on individual items and dimensions at the level of the governorates (Continued)

\begin{tabular}{|c|c|c|c|c|c|c|}
\hline & Capital & Hawalli & Farwaniya & Jahra & Ahmadi & $p$-value \\
\hline & Positive & Positive & Positive & Positive & Positive & \\
\hline & $n(\%)$ & n (\%) & n (\%) & n (\%) & n (\%) & \\
\hline \multicolumn{7}{|l|}{ 7. Communication About Prescriptions Across Shifts } \\
\hline $\begin{array}{l}\text { B4. We have clear expectations about exchanging } \\
\text { important prescription information across shifts }\end{array}$ & $22(81.5)$ & $67(76.1)$ & $33(67.3)$ & $19(70.4)$ & $44(73.3)$ & $0.682^{b}$ \\
\hline $\begin{array}{l}\text { B6. We have standard procedures for communicating } \\
\text { prescription information across shifts }\end{array}$ & $22(81.5)$ & $73(83.0)$ & $36(75.0)$ & $18(66.7)$ & $41(68.3)$ & $0.197^{b}$ \\
\hline $\begin{array}{l}\text { B14. The status of problematic prescriptions is well } \\
\text { communicated across shifts }\end{array}$ & $20(74.1)$ & $67(76.1)$ & $39(81.3)$ & $17(63.0)$ & $42(70.0)$ & $0.444^{b}$ \\
\hline Dimension positivity (\%) & 79.0 & 78.4 & 74.5 & 66.7 & 70.5 & $0.131^{\mathrm{b}}$ \\
\hline \multicolumn{7}{|l|}{ 8. Communication About Mistakes } \\
\hline B8. Staff in this pharmacy discuss mistakes & $22(81.5)$ & $72(80.9)$ & $43(86.0)$ & $24(88.9)$ & $51(85.0)$ & $0.842^{\mathrm{b}}$ \\
\hline $\begin{array}{l}\text { B13. When patient safety issues occur in this } \\
\text { pharmacy, staff discuss them }\end{array}$ & $24(88.9)$ & $63(70.8)$ & $42(84.0)$ & $24(88.9)$ & $53(89.8)$ & $0.019^{b}$ \\
\hline $\begin{array}{l}\text { B15. In this pharmacy, we talk about ways to } \\
\text { prevent mistakes from happening again }\end{array}$ & $26(96.3)$ & $71(79.8)$ & $39(79.6)$ & $22(81.5)$ & $43(71.7)$ & $0.133^{b}$ \\
\hline Dimension positivity (\%) & 88.9 & 77.2 & 83.2 & 86.4 & 82.2 & $0.093^{b}$ \\
\hline \multicolumn{7}{|l|}{ 9. Response to Mistakes } \\
\hline C1. Staff are treated fairly when they make mistakes & $23(88.5)$ & $83(93.3)$ & $47(95.9)$ & $24(88.9)$ & $58(96.7)$ & $0.405^{\mathrm{a}}$ \\
\hline $\begin{array}{l}\text { C4. This pharmacy helps staff learn from their } \\
\text { mistakes rather than punishing them }\end{array}$ & $25(92.6)$ & $82(93.2)$ & $46(93.9)$ & $26(96.3)$ & $55(91.7)$ & $0.973^{\mathrm{a}}$ \\
\hline $\begin{array}{l}\text { C7. We look at staff actions and the way we do } \\
\text { things to understand why mistakes happen in this } \\
\text { pharmacy }\end{array}$ & $24(88.9)$ & $83(93.3)$ & $41(83.7)$ & $24(88.9)$ & $48(80.0)$ & $0.169^{\mathrm{a}}$ \\
\hline $\begin{array}{l}\text { C8. Staff feel like their mistakes are held against } \\
\text { them (R) }\end{array}$ & $21(77.8)$ & $63(74.1)$ & $34(70.8)$ & $24(88.9)$ & $44(73.3)$ & $0.482^{b}$ \\
\hline Dimension positivity (\%) & 87.0 & 85.3 & 86.1 & 90.8 & 85.4 & $0.607^{\mathrm{b}}$ \\
\hline \multicolumn{7}{|l|}{ 10. Organizational Learning - Continuous Improvement } \\
\hline $\begin{array}{l}\text { C2. When a mistake happens, we try to figure out } \\
\text { what problems in the work process led to the } \\
\text { mistake }\end{array}$ & $24(88.9)$ & $85(95.5)$ & $46(93.9)$ & $26(96.3)$ & $56(93.3)$ & $0.766^{\mathrm{a}}$ \\
\hline $\begin{array}{l}\text { C5. When the same mistake keeps happening, we } \\
\text { change the way we do things }\end{array}$ & $24(24.3)$ & $79(89.8)$ & $40(81.6)$ & $25(92.6)$ & $58(96.6)$ & $0.132^{\mathrm{a}}$ \\
\hline $\begin{array}{l}\text { C10. Mistakes have led to positive changes in this } \\
\text { pharmacy }\end{array}$ & $27(100.0)$ & $82(93.2)$ & $46(95.8)$ & $26(96.3)$ & $57(95.0)$ & $0.807^{\mathrm{a}}$ \\
\hline Dimension positivity (\%) & 71.1 & 92.8 & 90.4 & 95.1 & 95.0 & $0.522^{b}$ \\
\hline \multicolumn{7}{|l|}{ 11. Overall Perceptions of Patient Safety } \\
\hline $\begin{array}{l}\text { C3. This pharmacy places more emphasis on sales } \\
\text { than on patient safety (R) }\end{array}$ & $22(84.6)$ & $70(82.4)$ & $31(62.0)$ & $17(63.0)$ & $35(58.3)$ & $0.005^{\mathrm{b}}$ \\
\hline C6. This pharmacy is good at preventing mistakes & $25(92.6)$ & $85(95.5)$ & $49(98.0)$ & $26(96.3)$ & $57(95.0)$ & $0.858^{\mathrm{a}}$ \\
\hline $\begin{array}{l}\text { C9. The way we do things in this pharmacy reflects } \\
\text { a strong focus on patient safety }\end{array}$ & $27(100.0)$ & $83(94.3)$ & $49(98.0)$ & $25(92.6)$ & $58(96.7)$ & $0.603^{\mathrm{a}}$ \\
\hline Dimension positivity (\%) & 92.4 & 90.7 & 86 & 84 & 83.3 & $0.070^{\mathrm{b}}$ \\
\hline
\end{tabular}

(R): Negatively worded items were reversed coded

$p$-values were generated using ${ }^{\mathrm{a}}$ Fisher's exact test and ${ }^{\mathrm{b}}$ Pearson chi-square test Significant numbers from the statistical tests were presenetd in bold

hand, the average PRR for the dimensions "Patient Counselling" and "Response to Mistakes" were significantly lower among those who worked $40 \mathrm{~h}$ per week or less compared to their counterparts $(p=0.010$ and $p=0.013$, respectively). The PRR for the items "we feel rushed when processing prescriptions (B9)" and "interruptions/distractions in this pharmacy make it difficult for staff to work accurately (B16)" in the dimension "Staffing, Work 
Table 5 Positive response rate (PRR) for individual items/dimension according to pharmacists' experience in their present workplace

\begin{tabular}{|c|c|c|c|c|}
\hline & $<3$ years & $3-<6$ years & $\geq 6$ years & $p$-value \\
\hline & Positive & Positive & Positive & \\
\hline & $n(\%)$ & n (\%) & $n(\%)$ & \\
\hline \multicolumn{5}{|l|}{ 1. Physical Space and Environment } \\
\hline A1. This pharmacy is well organized & $117(92.9)$ & $59(93.7)$ & 57 (91.9) & $0.902^{\mathrm{a}}$ \\
\hline A5. This pharmacy is free of clutter/untidiness & $117(92.9)$ & $58(89.2)$ & $56(90.3)$ & $0.667^{b}$ \\
\hline $\begin{array}{l}\text { A7. The physical layout of this pharmacy supports good } \\
\text { workflow }\end{array}$ & $97(77.0)$ & $53(81.5)$ & $52(86.7)$ & $0.288^{\mathrm{b}}$ \\
\hline Total & $331(87.6)$ & $170(88.1)$ & $165(89.7)$ & $0.766^{\mathrm{b}}$ \\
\hline \multicolumn{5}{|l|}{ 2. Teamwork } \\
\hline A2. Staff treat each other with respect & $123(97.6)$ & $64(98.5)$ & $60(96.8)$ & $0.760^{\mathrm{a}}$ \\
\hline $\begin{array}{l}\text { A4. Staff in this pharmacy clearly understand their } \\
\text { roles and responsibilities }\end{array}$ & $121(96.0)$ & $62(96.9)$ & $58(95.2)$ & $0.662^{\mathrm{a}}$ \\
\hline A9. Staff work together as an effective team & $122(96.8)$ & $65(100.0)$ & 59 (95.2) & $0.245^{\mathrm{a}}$ \\
\hline Total & 366 (96.8) & 191 (98.5) & $186(95.2)$ & $0.187^{b}$ \\
\hline \multicolumn{5}{|l|}{ 3. Staff Training and Skills } \\
\hline $\begin{array}{l}\text { A3. Pharmacy assistants/helpers in this pharmacy receive } \\
\text { the training they need to do their jobs }\end{array}$ & $93(73.8)$ & $49(75.4)$ & $58(93.5)$ & $0.005^{\mathrm{b}}$ \\
\hline $\begin{array}{l}\text { A6. Staff in this pharmacy have the skills they need to } \\
\text { do their jobs well }\end{array}$ & $120(95.2)$ & $62(95.4)$ & $60(96.8)$ & $0.999^{\mathrm{a}}$ \\
\hline $\begin{array}{l}\text { A8. Staff who are new to this pharmacy receive adequate } \\
\text { orientation }\end{array}$ & $112(90.3)$ & 58 (90.6) & $53(88.3)$ & $0.894^{\mathrm{b}}$ \\
\hline A10. Staff get enough training from this pharmacy & $98(78.4)$ & $51(78.5)$ & $60(96.8)$ & $0.004^{\mathrm{b}}$ \\
\hline Total & $423(84.4)$ & $220(84.9)$ & $231(93.9)$ & $0.001^{\mathrm{b}}$ \\
\hline \multicolumn{5}{|l|}{ 4. Communication Openness } \\
\hline B1. Staff ideas and suggestions are valued in this pharmacy & $94(75.2)$ & $53(81.5)$ & $49(79.0)$ & $0.586^{\mathrm{b}}$ \\
\hline $\begin{array}{l}\text { B5. Staff feel comfortable asking questions when they are } \\
\text { unsure about something }\end{array}$ & $113(89.7)$ & $55(84.6)$ & $55(88.7)$ & $0.583^{\mathrm{b}}$ \\
\hline $\begin{array}{l}\text { B10. It is easy for staff to speak up to their pharmacy } \\
\text { manager (chief pharmacist) or pharmacy owner about } \\
\text { patient safety concerns in this pharmacy }\end{array}$ & $110(87.3)$ & $52(81.3)$ & $57(93.4)$ & $0.124^{b}$ \\
\hline Total & $317(84.1)$ & $160(82.5)$ & $161(87.0)$ & $0.462^{\mathrm{b}}$ \\
\hline \multicolumn{5}{|l|}{ 5. Patient Counselling } \\
\hline $\begin{array}{l}\text { B2. Pharmacists in this pharmacy encourage patients to } \\
\text { talk about their medications }\end{array}$ & $117(92.9)$ & $57(87.7)$ & $52(83.9)$ & $0.152^{b}$ \\
\hline $\begin{array}{l}\text { B7. Our pharmacists spend enough time talking to } \\
\text { patients about how to use their medications }\end{array}$ & $118(93.7)$ & $60(92.3)$ & $56(90.3)$ & $0.707^{\mathrm{a}}$ \\
\hline $\begin{array}{l}\text { B11. Our pharmacists tell patients important information } \\
\text { about their new prescriptions }\end{array}$ & $117(92.9)$ & $57(87.7)$ & $56(90.3)$ & $0.492^{b}$ \\
\hline Total & $352(93.1)$ & $174(89.2)$ & $164(88.2)$ & $0.101^{b}$ \\
\hline \multicolumn{5}{|l|}{ 6. Staffing, Work Pressure, and Pace } \\
\hline B3. Staff take adequate breaks during their shifts & $37(29.4)$ & $25(38.5)$ & $45(72.6)$ & $<0.001^{\mathrm{b}}$ \\
\hline B9. We feel rushed when processing prescriptions (R) & $59(47.2)$ & $24(36.9)$ & $14(22.6)$ & $0.005^{\mathrm{b}}$ \\
\hline B12. We have enough staff to handle the workload & $107(84.9)$ & $53(82.8)$ & $50(80.6)$ & $0.754^{\mathrm{b}}$ \\
\hline $\begin{array}{l}\text { B16. Interruptions/distractions in this pharmacy (from } \\
\text { phone calls, faxes, customers, etc.) make it difficult for } \\
\text { staff to work accurately (R) }\end{array}$ & $44(35.2)$ & $18(28.1)$ & $6(9.7)$ & $0.001^{\mathrm{b}}$ \\
\hline Total & $247(49.2)$ & $120(46.5)$ & $115(46.4)$ & $0.680^{\mathrm{b}}$ \\
\hline
\end{tabular}


Table 5 Positive response rate (PRR) for individual items/dimension according to pharmacists' experience in their present workplace (Continued)

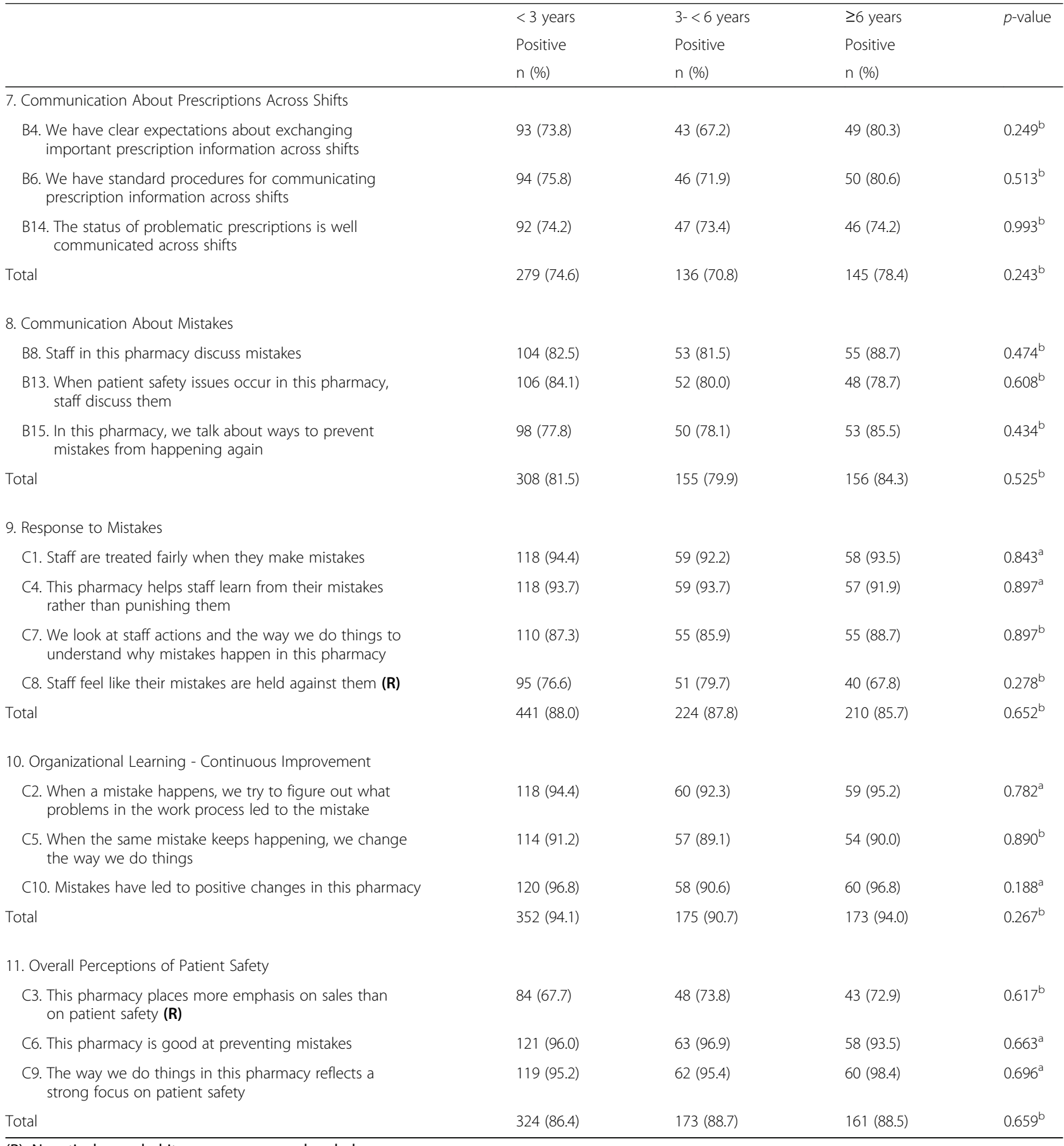

(R): Negatively worded items were reversed coded

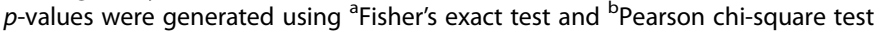

Significant numbers from the statistical tests were presenetd in bold

Pressure, and Pace" were significantly lower among those pharmacists who worked less than $40 \mathrm{~h}$ per week compared to those who worked for longer hours, $p=0.048$ ).

The overall grade of patient safety rating given by the pharmacists to their pharmacy was very high (Good 25.3\%, Very good 50.2\% and Excellent 20.6\%). There were no significant differences in ratings according to the years of experience or the hours they work in the pharmacy.

\section{Discussion}

This study is the first of its kind in Kuwait to report data on the community pharmacists' perspectives of patient 
Table 6 Positive response rate (PRR) for individual items/dimensions according to pharmacists' working hours per week

\begin{tabular}{|c|c|c|c|}
\hline & 32-40 h per week & $>40 \mathrm{~h}$ per week & $p$-value \\
\hline & Positive & Positive & \\
\hline & $n(\%)$ & $n(\%)$ & \\
\hline \multicolumn{4}{|l|}{ 1. Physical Space and Environment } \\
\hline A1. This pharmacy is well organized & 25 (92.6) & $208(92.9)$ & $0.999^{\mathrm{a}}$ \\
\hline A5. This pharmacy is free of clutter/untidiness & $26(92.9)$ & $205(91.1)$ & $0.999^{\mathrm{a}}$ \\
\hline $\begin{array}{l}\text { A7. The physical layout of this pharmacy supports good } \\
\text { workflow }\end{array}$ & $24(88.9)$ & $178(79.5)$ & $0.243^{b}$ \\
\hline Total & $75(91.5)$ & $591(87.8)$ & $0.333^{b}$ \\
\hline \multicolumn{4}{|l|}{ 2. Teamwork } \\
\hline A2. Staff treat each other with respect & $28(100.0)$ & $219(97.3)$ & $0.999^{\mathrm{a}}$ \\
\hline $\begin{array}{l}\text { A4. Staff in this pharmacy clearly understand their roles } \\
\text { and responsibilities }\end{array}$ & $26(96.3)$ & $215(95.6)$ & $0.999^{\mathrm{a}}$ \\
\hline A9. Staff work together as an effective team & $28(100.0)$ & $218(96.9)$ & $0.999^{\mathrm{a}}$ \\
\hline Total & $82(98.8)$ & $652(96.6)$ & $0.503^{\mathrm{a}}$ \\
\hline \multicolumn{4}{|l|}{ 3. Staff Training and Skills } \\
\hline $\begin{array}{l}\text { A3. Pharmacy assistants/helpers in this pharmacy receive } \\
\text { the training they need to do their jobs }\end{array}$ & $26(92.9)$ & $174(77.3)$ & $0.057^{b}$ \\
\hline $\begin{array}{l}\text { A6. Staff in this pharmacy have the skills they need to } \\
\text { do their jobs well }\end{array}$ & $27(96.4)$ & $215(95.6)$ & $0.999^{\mathrm{a}}$ \\
\hline $\begin{array}{l}\text { A8. Staff who are new to this pharmacy receive adequate } \\
\text { orientation }\end{array}$ & $25(92.6)$ & $198(89.6)$ & $0.999^{\mathrm{a}}$ \\
\hline A10. Staff get enough training from this pharmacy & $26(92.9)$ & $183(81.7)$ & $0.185^{\mathrm{a}}$ \\
\hline Total & $104(93.7)$ & $770(86.0)$ & $0.024^{b}$ \\
\hline \multicolumn{4}{|l|}{ 4. Communication Openness } \\
\hline B1. Staff ideas and suggestions are valued in this pharmacy & $22(81.5)$ & $174(77.3)$ & $0.624^{b}$ \\
\hline $\begin{array}{l}\text { B5. Staff feel comfortable asking questions when they are } \\
\text { unsure about something }\end{array}$ & $24(85.7)$ & $199(88.4)$ & $0.755^{\mathrm{a}}$ \\
\hline $\begin{array}{l}\text { B10. It is easy for staff to speak up to their pharmacy } \\
\text { manager (chief pharmacist) or pharmacy owner about } \\
\text { patient safety concerns in this pharmacy }\end{array}$ & $23(82.1)$ & $196(87.9)$ & $0.373^{\mathrm{a}}$ \\
\hline Total & $69(83.1)$ & $569(84.5)$ & $0.738^{b}$ \\
\hline \multicolumn{4}{|l|}{ 5. Patient Counselling } \\
\hline $\begin{array}{l}\text { B2. Pharmacists in this pharmacy encourage patients to } \\
\text { talk about their medications }\end{array}$ & $23(82.1)$ & $203(90.2)$ & $0.196^{\mathrm{a}}$ \\
\hline $\begin{array}{l}\text { B7. Our pharmacists spend enough time talking to } \\
\text { patients about how to use their medications }\end{array}$ & $24(85.7)$ & $210(93.3)$ & $0.242^{\mathrm{a}}$ \\
\hline $\begin{array}{l}\text { B11. Our pharmacists tell patients important information } \\
\text { about their new prescriptions }\end{array}$ & $23(82.1)$ & $207(92.0)$ & $0.152^{\mathrm{a}}$ \\
\hline Total & $70(83.3)$ & $620(91.9)$ & $0.010^{\mathrm{b}}$ \\
\hline \multicolumn{4}{|l|}{ 6. Staffing, Work Pressure, and Pace } \\
\hline B3. Staff take adequate breaks during their shifts & $19(67.9)$ & $88(39.1)$ & $0.004^{b}$ \\
\hline B9. We feel rushed when processing prescriptions (R) & $5(17.9)$ & $92(41.1)$ & $0.017^{b}$ \\
\hline B12. We have enough staff to handle the workload & $23(82.1)$ & $187(83.5)$ & $0.792^{\mathrm{a}}$ \\
\hline $\begin{array}{l}\text { B16. Interruptions/distractions in this pharmacy (from } \\
\text { phone calls, faxes, customers, etc.) make it difficult for } \\
\text { staff to work accurately (R) }\end{array}$ & $3(11.1)$ & $65(29.0)$ & $0.048^{b}$ \\
\hline Total & $50(45.0)$ & $432(48.2)$ & $0.061^{b}$ \\
\hline
\end{tabular}


Table 6 Positive response rate (PRR) for individual items/dimensions according to pharmacists' working hours per week (Continued)

\begin{tabular}{|c|c|c|c|}
\hline & $32-40 \mathrm{~h}$ per week & $>40$ h per week & $p$-value \\
\hline & Positive & Positive & \\
\hline & $n(\%)$ & $n(\%)$ & \\
\hline \multicolumn{4}{|l|}{ 7. Communication About Prescriptions Across Shifts } \\
\hline $\begin{array}{l}\text { B4. We have clear expectations about exchanging important } \\
\text { prescription information across shifts }\end{array}$ & $24(85.7)$ & $161(72.2)$ & $0.126^{b}$ \\
\hline $\begin{array}{l}\text { B6. We have standard procedures for communicating } \\
\text { prescription information across shifts }\end{array}$ & $21(77.8)$ & $169(75.8)$ & $0.819^{b}$ \\
\hline $\begin{array}{l}\text { B14. The status of problematic prescriptions is well } \\
\text { communicated across shifts }\end{array}$ & $20(74.1)$ & $165(74.0)$ & $0.993^{b}$ \\
\hline Total & $65(79.3)$ & $495(74.0)$ & $0.300^{b}$ \\
\hline \multicolumn{4}{|l|}{ 8. Communication About Mistakes } \\
\hline B8. Staff in this pharmacy discuss mistakes & $21(75.0)$ & $191(84.9)$ & $0.181^{\mathrm{a}}$ \\
\hline $\begin{array}{l}\text { B13. When patient safety issues occur in this pharmacy, } \\
\text { staff discuss them }\end{array}$ & $23(82.1)$ & $183(81.7)$ & $0.954^{b}$ \\
\hline $\begin{array}{l}\text { B15. In this pharmacy, we talk about ways to prevent } \\
\text { mistakes from happening again }\end{array}$ & $24(85.7)$ & $177(79.0)$ & $0.406^{b}$ \\
\hline Total & $68(81.0)$ & $551(81.9)$ & $0.837^{\mathrm{b}}$ \\
\hline \multicolumn{4}{|l|}{ 9. Response to Mistakes } \\
\hline C1. Staff are treated fairly when they make mistakes & $24(88.9)$ & $211(94.2)$ & $0.392^{\mathrm{a}}$ \\
\hline $\begin{array}{l}\text { C4. This pharmacy helps staff learn from their mistakes } \\
\text { rather than punishing them }\end{array}$ & $24(85.7)$ & $210(94.2)$ & $0.106^{\mathrm{a}}$ \\
\hline $\begin{array}{l}\text { C7. We look at staff actions and the way we do things to } \\
\text { understand why mistakes happen in this pharmacy }\end{array}$ & $25(89.3)$ & $195(87.1)$ & $0.999^{\mathrm{a}}$ \\
\hline C8. Staff feel like their mistakes are held against them (R) & $15(55.6)$ & $171(77.7)$ & $0.012^{b}$ \\
\hline Total & $88(80.0)$ & $787(88.3)$ & $0.013^{b}$ \\
\hline \multicolumn{4}{|l|}{ 10. Organizational Learning - Continuous Improvement } \\
\hline $\begin{array}{l}\text { C2. When a mistake happens, we try to figure out what } \\
\text { problems in the work process led to the mistake }\end{array}$ & $25(89.3)$ & $212(94.6)$ & $0.224^{\mathrm{a}}$ \\
\hline $\begin{array}{l}\text { C5. When the same mistake keeps happening, we change } \\
\text { the way we do things }\end{array}$ & $23(85.2)$ & $202(91.0)$ & $0.308^{\mathrm{a}}$ \\
\hline C10. Mistakes have led to positive changes in this pharmacy & $27(96.4)$ & $211(95.0)$ & $0.999^{\mathrm{a}}$ \\
\hline Total & $75(90.4)$ & $625(93.6)$ & $0.274^{b}$ \\
\hline \multicolumn{4}{|l|}{ 11. Overall Perceptions of Patient Safety } \\
\hline $\begin{array}{l}\text { C3. This pharmacy places more emphasis on sales than on } \\
\text { patient safety (R) }\end{array}$ & $20(74.1)$ & $155(70.1)$ & $0.672^{b}$ \\
\hline C6. This pharmacy is good at preventing mistakes & $25(89.3)$ & $217(96.4)$ & $0.109^{\mathrm{a}}$ \\
\hline $\begin{array}{l}\text { C9. The way we do things in this pharmacy reflects a } \\
\text { strong focus on patient safety }\end{array}$ & $26(96.3)$ & $215(96.0)$ & $0.999^{\mathrm{a}}$ \\
\hline Total & $71(86.6)$ & $587(87.6)$ & $0.791^{b}$ \\
\hline
\end{tabular}

(R): Negatively worded items were reversed coded

$p$-values were generated using a Fisher's exact test and ${ }^{\mathrm{b}}$ Pearson chi-square test

Significant numbers from the statistical tests were presenetd in bold

safety culture in their practice. Furthermore, the third publication of its kind using the PSOPSC to explore patient safety culture in the setting of community pharmacies [21,22], following the piloting of the questionnaire in 60 US pharmacies approximately 6 years ago during the development of the study tool [23]. Although many questionnaires were developed to assess patient safety culture, they are generally focused toward healthcare organizations as a whole and are not customized to specific departments within an organization [13]. PSOPSC is a very comprehensive survey and community pharmacy specific. 
The response rate in the present study was $99.0 \%$, which was higher than that of previous studies [17-19, $24,25]$, including the study in Malaysian retail pharmacies (93.52\%) [21] and the AHRQ study (75.0\%). The higher response rate in the study can be due to the fact that the questionnaires were distributed in-person by the researcher. This contrasts to online surveys used for data collection in the previous studies [25, 26]. Many community pharmacists were requested to complete the questionnaire during the overnight shifts when pharmacists did not have much customers, hence, they had sufficient time to fill out the questionnaire.

For the 36 items of the questionnaire, an overall mean of $83.3 \%$ was scored for patient safety culture which is higher than that in earlier studies conducted in Malaysia [21] and China [24] . This reflects that the pharmacists working at the community pharmacy understood the importance and values of patient safety in their practice. Findings in the current study also showed that there was a significant variability in the PRR values across the dimensions of patient safety. In line with other local [17-19] and international studies [21, 27], the highest PRR was seen in the "Teamwork" domain (96.8\%), suggesting that the concept of teamwork is universally positive in the practice of pharmacy. This was followed by the domains of "Organizational Learning-Continuous Improvement" and "Patient Counselling" scoring 93.2 and $90.9 \%$ respectively, which highlight the existence of a learning culture among practicing pharmacists to improve the services which in turn can enhance the patient safety. In addition, patient counselling is the core of pharmacy practice in the community pharmacies in Kuwait and community pharmacists expressed their engagement and willingness to spend enough time with patients to discuss about their medications. With this respect, studies have shown that community pharmacists' interventions can reflect positively on patients' adherence to medications and subsequently their therapeutic outcomes [28].

The lowest PRR was given to the "Staffing, Work Pressure, and Pace" domain which scored $49.7 \%$, close to the study from Malaysia [21]. In particular, the frequent interruptions or distractions in the pharmacy, feeling rushed when processing prescriptions and inadequate breaks during shifts were given the lowest PRR of 27.1, 38.5 , and $42.3 \%$, respectively. In addition, pharmacists working for more than $40 \mathrm{~h}$ per week had significantly lower PRR on the adequacy of breaks during shifts (Table 6). The environment of the pharmacy was a significant factor related to medication errors [29-31] and increased dispensing errors were reported where there was unfavourable working environment [32]. Taking this into account, all community pharmacists in Kuwait and elsewhere should be supported by a favourable workplace to allow them to work more efficiently.
At the level of governorates, there was a significant discrepancy in responses of community pharmacists from the five governorates on some items of the "Staffing, Work Pressure, and Pace" domains. Although the majority agreed that the pharmacy had enough staff, the Capital and Hawalli governorates scored the lowest in the items of pharmacists feeling rushed when processing prescriptions and having frequent interruptions, while Farwaniya, Jahra and Ahmadi had the lowest scores with regards to inadequate breaks during shifts. This could be partly explained by uneven proportion of the community pharmacy distribution across governorates as opposed to population number. For example, according to the last published Annual Health Report of Kuwait [33], Farwaniya was the most populous governorate, with a population size of 1,032,082, followed by Ahmadi, Hawalli, Capital and lastly Jahra. In comparison, the total number of community pharmacies in Farwaniya region was 89 (as compared to 160 in Hawalli, 109 in Ahmadi, 48 in Capital and 48 in Jahra) according to the data obtained during the preliminary fieldwork from the $\mathrm{MoH}$, Kuwait in 2017. Therefore, results from the study suggest the need for accurate planning for the distribution of community pharmacies in Kuwait, and in other countries, to target the population size in each region.

The "Communication about Prescriptions across Shifts" and "Communication about Mistakes" dimensions showed relatively lower scores of 74.6 and $81.8 \%$, respectively, which indicates the need for improvement. In dispensing medications, effective communication is crucial to minimize drug related problems. Pharmacy staff should learn from each other's by knowing their own responsibilities as well as engaging in discussing mistakes and providing feedback. The mutual understanding among working staff on patient safety issues and knowledge on sources of mistakes and ways of detecting and preventing them will enhance the patient safety [34]. Also, results from the study showed that regardless of their seriousness, there was a minimal documentation of mistakes carried out in the community pharmacies. The $\mathrm{MoH}$ in Kuwait should have a proactive role in setting specific policies and guidelines for strategies that should be followed when identifying and communicating mistakes, similar to other international communities [35].

The work experience level and length of working hours are closely related to the relative occurrence of the patient-related risk events [36-38]. This study tested pharmacists' PRR on safety culture items in respect to experience years and working hours per week. Pharmacists with more work experience (a minimum of 6 years of experience) scored better PRR for items relevant to adequacy of training and breaks during shifts. This could be related to the fact that their seniority in 
work allowed them to master pharmacy workload and tasks more than those with less years of experience. In line with this, senior pharmacists in the study by Jia et al. [24] gave significantly higher PRR scores on the item of staff taking adequate breaks during shifts. These results suggest the importance of providing less experienced community pharmacists with adequate training and breaks during shifts to handle workload and to minimize errors.

\section{Study strengths and limitations}

This study is the first in the community pharmacy setting in Kuwait and included a large heterogeneous sample of community pharmacists from all over the country. Thus, taking the overall response rate into account (99.0\%), the study results can be considered as the representative of the target population of community pharmacists. The selection of the pharmacies was done randomly from the original list provided.

Taking into consideration that all of the community pharmacists in the study were non-citizens, authors think that the results of the study might have inflated the real picture of safety culture in community pharmacies in Kuwait. The use of questionnaires as data collection tool has a disadvantage of response bias [39] and authors think that the risk is higher in the study due to the fear of the impact of negative responses on the pharmacies' reputation and consequently pharmacists' job security. This could have been reduced if the survey method for data collection was combined with another method, such as observation (i.e. triangulation method) which would have been validated the data presented in the study [39]. Therefore, repeating the study with a triangulation approach would be a validation approach in future research. In addition, testing the impact of having low-rated domains of safety culture on patient safety was out of the scope of the current study. Hence, evaluating the consequences of weakness in certain safety culture domains on patient safety and the quality of healthcare services should be considered in future research.

The study has only included the responses of community pharmacists, hence the responses of pharmacists working in other settings, such as private or government hospitals where workflow and responsibilities might differ. Hence, results from this study cannot be generalized to pharmacists working in other settings.

\section{Conclusion}

Understanding patient safety culture from the perspectives of community pharmacists can help identify areas of weakness and can support decision for improvements. Our results suggest that pharmacies in Kuwait should develop strategies and plans to improve aspects of patient safety such as communication about prescriptions throughout shifts and responses against mistakes and create a positive culture that encourages patient's safety in this setting. Urgent attention should be given to the areas of weakness in the patient safety, which has been observed mainly in the dimension of Staffing, Work Pressure, and Pace. With this respect, stakeholders should undertake the required steps towards supporting community pharmacists with adequate number of staff and with organized less distractible environment in order to perform their work accurately without jeopardizing patient safety.

\section{Additional file}

Additional File 1: Safety Culture Questionnaire, community pharmacy version. The PSOPSC, developed by the AHRQ is a self-administered validated tool that measures 11 dimensions ( 36 items) of patient safety culture. (DOC $210 \mathrm{~kb}$ )

\section{Abbreviations \\ ACl: Accreditation Canada International; ADE: adverse drug events; AHRQ: Agency for Healthcare Research and Quality; HSC: Health Science Centre; IOM: Institute of Medicine; IQR: Interquartile range; JCl: Joint Commission International; $\mathrm{MoH}$ : Ministry of Health; PRR: Positive response rate; PSOPSC: Pharmacy Survey on Patient Safety Culture; SD: standard deviation; SPSS: Statistical Package for Social Science; WHO: World Health Organization}

\section{Acknowledgements \\ Authors would like to thank all the community pharmacists who participated in this study. They also gratefully acknowledge the $\mathrm{MoH}$, Kuwait, for the continuous collaboration and support.}

\section{Funding}

No funding was provided for conducting this study.

\section{Availability of data and materials}

The datasets used and/or analysed during the current study are available from the corresponding author on reasonable request.

\section{Ethical approval and consent to participate}

Ethical clearance was sought from the Standing Committee for Coordination of Health and Medical Research, $\mathrm{MOH}$ and the Health Science Centre (HSC) Ethics Committee for Student Research, Kuwait University, Kuwait. Informed consents were obtained from all surveyed participants. For those who agreed to participate, a written informed consent form which clearly assured the participants regarding the confidentiality and anonymity of the gathered information was obtained.

\section{Authors' contribution}

FA and EA contributed to the research idea, study design, data interpretation and analysis, and manuscript development and review; HA and MA contributed to data collection and review; NA contributed to the manuscript development and review. All authors approved the final version of the manuscript.

\section{Authors' information}

FA - PhD., Assistant Professor at the Department of Pharmacy Practice, Faculty of Pharmacy, Kuwait University, Kuwait.

EA - PhD., Senior Clinical Lecturer at the Faculty of Pharmacy, Kuwait University, Kuwait.

HA and MA - BSc., pharmacy student at the Faculty of Pharmacy, Kuwait University. Kuwait. 
NA- PhD, Assistant Professor at the Department of Clinical Pharmacy Research, Institute for Research and Medical Consultations (IRMC), Imam Abdulrahman Bin Faisal University, Dammam, Saudi Arabia.

\section{Consent for publication}

Not applicable.

\section{Competing interests}

The authors declare that they have no competing interests.

\section{Publisher's Note}

Springer Nature remains neutral with regard to jurisdictional claims in published maps and institutional affiliations.

\section{Author details}

${ }^{1}$ Department of Pharmacy Practice, Faculty of Pharmacy, Kuwait University, P.O. Box 24923, 13110 Safat, Kuwait. ${ }^{2}$ Department of Clinical Pharmacy Research, Institute for Research and Medical Consultations (IRMC), Imam Abdulrahman Bin Faisal University, P.O. Box 1982, 31441 Dammam, Saudi Arabia.

Received: 1 July 2018 Accepted: 29 October 2018

Published online: 22 November 2018

\section{References}

1. IOM. To Err is Human: Building a Safer Health System. Washington (DC): National Academies PRess (US); 2000.

2. Assiri GA, Shebl NA, Mahmoud MA, et al. What is the epidemiology of medication errors, error-related adverse events and risk factors for errors in adults managed in community care contexts? A systematic review of the international literature BMJ Open. 2018;8:e019101.

3. Bond CA, Raehl CL, Franke T. Clinical pharmacy services, hospital pharmacy staffing, and medication errors in United States hospitals. Pharmacotherapy. 2002;22:134-47.

4. Sammer CE, Lykens $K$, Singh KP, Mains DA, Lackan NA. What is patient safety culture? A review of the literature. J Nurs Scholarsh. 2010;42:156-65.

5. Al-Tajir GK, Kelly WN. Epidemiology, comparative methods of detection, and preventability of adverse drug events. Ann Pharmacother. 2005;39:1169-74.

6. Avery AJ, Rodgers S, Cantrill JA, et al. A pharmacist-led information technology intervention for medication errors (PINCER): a multicentre, cluster randomised, controlled trial and cost-effectiveness analysis. Lancet. 2012;379:1310-9.

7. De Oliveira GSJ, Castro-Alves LJ, Kendall MC, et al. Effectiveness of pharmacist intervention to reduce medication errors and health-care resources utilization after transitions of care: a meta-analysis of randomized controlled trials. J Patient Saf. 2017. https://doi.org/10.1097/pts. 0000000000000283.

8. Nieva VF, Sorra J. Safety culture assessment: a tool for improving patient safety in healthcare organizations. Qual Saf Health Care. 2003;12(Suppl 2): ii $17-23$.

9. Clarke S. Perceptions of organizational safety: implications for the development of safety culture. J Org Behav. 1999;20:185-98.

10. Ashcroft DM, Morecroft C, Parker D, et al. Safety culture assessment in community pharmacy: development, face validity, and feasibility of the Manchester patient safety assessment framework. Qual Saf Health Care. 2005; 14:417-21.

11. Singla A, Kitch BT, Weissman SW. Assessing patient safety culture: a review and synthesis of the measurement tools. J Patient Saf. 2006;2:105-15.

12. Weingart SN, Farbstein K, Davis RB, Phillips RS. Using a multihospital survey to examine the safety culture. Jt Comm J Qual Patient Saf. 2004;30:125-32.

13. Colla JB, Bracken AC, Kinney LM, et al. Measuring patient safety climate: a review of surveys. Qual Saf Health Care. 2005;14:364-6.

14. Morello RT, Lowthian JA, Barker AL, et al. Strategies for improving patient safety culture in hospitals: a systematic review. BMJ Qual Saf. 2013;22:11-8.

15. Elmontsri M, Almashrafi $A$, Banarsee $R$, et al. Status of patient safety culture in Arab countries: a systematic review. BMJ Open. 2017;7:e013487.

16. IMTJ. Accreditation Canada helps Kuwait to improve healthcare quality. 2009. Available at: https://www.imtj.com/news/accreditation-canadahelping-kuwait-improve-healthcare-quality. Accessed 17 Jan 2018.
17. Badr HE, AlFadalah T, El-Jardali F. Towards promoting patient safety practices: baseline assessment of patient safety culture in three hospitals. Int J Healthc Manag. 2017. https://doi.org/10.1080/20479700.2017.1390958.

18. Ghobashi M, El-ragehy $H$, Mosleh $H$, et al. Assessment of Patient Safety Culture in Primary Health Care Settings in Kuwait. Epidemiol Biostat Public Health. 2014;11(e 910 1):1-9.

19. Ali H, Ibrahem SZ, Al Mudaf B, Al Fadalah T, Jamal D, El-Jardali F. Baseline assessment of patient safety culture in public hospitals in Kuwait. BMC Health Serv Res. 2018;18:158. https://doi.org/10.1186/s12913-018-2960-x.

20. AHRQ. About surveys on patient safety (SOPS). 2012. Available at: https:// www.ahrq.gov/sops/quality-patient-safety/patientsafetyculture/index.html. Accessed 12 Dec 2017

21. Sivanandy P, Maharajan MK, Rajiah K, et al. Evaluation of patient safety culture among Malaysian retail pharmacists: results of a self-reported survey. Patient Prefer Adherence. 2016;10:1317-25.

22. Aboneh EA, Stone JA, Lester CA, et al. Evaluation of patient safety culture in community pharmacies. J Patient Saf. 2017. https://doi.org/10.1097/PTS. 0000000000000245

23. $A H R Q$. Pharmacy survey on patient safety culture: preliminary comparative results. 2012. Available at: https://www.ahrq.gov/professionals/quality-patientsafety/patientsafetyculture/pharmacy/2012/index.html. Accessed 12 Dec 2017.

24. Jia P, Zhang LH, Zhang MM, et al. Safety culture in a pharmacy setting using a pharmacy survey on patient safety culture: a cross-sectional study in China. BMJ Open. 2014;4:e004904.

25. Herner SJ, Rawlings JE, Swartzendruber K, et al. Pharmacy survey on patient safety culture: benchmarking results. J Patient Saf. 2017;13:37-42.

26. Nulty D. The adequacy of response rates to online and paper surveys: what can be done? Assess Eval High Educ. 2008;33:301-14.

27. Chen IC, Li HH. Measuring patient safety culture in Taiwan using the hospital survey on patient safety culture (HSOPSC). BMC Health Serv Res. 2010;10:152. https://doi.org/10.1186/1472-6963-10-152.

28. Taitel M, Jiang J, Rudkin K, et al. The impact of pharmacist face-to-face counseling to improve medication adherence among patients initiating statin therapy. Patient Prefer Adherence. 2012;6:323-9.

29. Pervanas $\mathrm{H}$, Alotaibi A. Evaluation of medication errors in community pharmacy settings: a retrospective report. J Pharm Technol. 2016;32:71-4.

30. Shahrokhi A, Ebrahimpour F, Ghodousi A. Factors effective on medication errors: a nursing view. J Res Pharm Pract. 2013;2:18-23.

31. Nguyen EE, Connolly PM, Wong V. Medication safety initiative in reducing medication errors. J Nurs Care Qual. 2010;25:224-30.

32. Aldhwaihi $K$, Schifano F, Pezzolesi C, et al. A systematic review of the nature of dispensing errors in hospital pharmacies. Integr Pharm Res Pract. 2016;5:1-10.

33. $\mathrm{MoH}$. Annual Health Report. National Centre for Health Information, Health \& Vital Statistics Division Kuwait. 2013. Available at: https://www.moh.gov. kw/Renderers/ShowPdf.ashx?ld=743523d6-e654-4b95-8640-bcb6879b57e9. Accesed 15 Jun 2018.

34. Bao N, Shao H, Nie X, et al. Analysis of the status of clinical pharmacist pilot training in Chinese hospitals. J Chin Pharm Sci. 2011;20:410-4.

35. Siang C, Kee W, Gee L, Richard Y, See HJ. Implementation of the benchmarking guidelines on community pharmacies in Malaysia. Malaysian Journal of Pharmaceutical Sciences. 2008;6:13-31.

36. Beso A, Franklin BD, Barber N. The frequency and potential causes of dispensing errors in a hospital pharmacy. Pharm World Sci. 2005;27:182-90.

37. Carlton G, Blegen MA. Medication-related errors: a literature review of incidence and antecedents. Annu Rev Nurs Res. 2006;24:19-38.

38. Olds DM, Clarke SP. The effect of work hours on adverse events and errors in health care. J Saf Res. 2010;41:153-62.

39. Smith F. Conducting your pharmacy practice research project- a step-bystep guide: Pharmaceutical Press UK; 2010. 